\title{
O Laboratório de Defesa Química do Exército - Desafios DA IDENTIFICAÇÃO INEQUIIVOCA DE AGENTES QUÍMICOS DE GUERRA
}

\author{
Tenente Coronel Farmacêutica Maria Ângela Furtado*, Major Farmacêutica Vânia Tira-Picos \\ LabDefQE, Laboratório de Defesa Química do Exército \\ furtado.ma@mail.exercito.pt
}

\begin{abstract}
The Chemical Defense Laboratory of the Army - challenges in the unambiguous identification of chemical warfare agents - Toxic chemicals have been used for various nefarious purposes since Antiquity but only since the First World War have sophisticated mechanisms been developed for their application as "chemical weapons".

More recently, the NATO forces, including Portugal, have been developing protection systems that minimize the number of military casualties caused by these weapons.

The use of chemical warfare agents has also spread to the civilian sector, due to the ease of their production and to the possible misuse of the facilities of chemical industries for illicit purposes. This situation led to the need to implement measures for protection of the civilian population.

The Laboratory of Chemical Defense (LabDefQE) is integrated in the division of Biological, Chemical and Radiological Defense of the Army, with the mission of unambiguous identification of chemical agents. This laboratory is a central organ for making medical, military and political decisions.

This article summarizes the activities of LabDefQE, and discusses certain technical and analytical challenges inherent in the processing of samples acquired in scenarios in which chemical agents have been used.
\end{abstract}

Os agentes químicos tóxicos são utilizados para diversos fins nefastos desde a Antiguidade. No entanto, só a partir da I Guerra Mundial se começaram a desenvolver mecanismos sofisticados para a sua utilização como "armas químicas”. Mais recentemente, as forças NATO incluindo Portugal, têm vindo a desenvolver sistemas de protecção das suas forças, no sentido de minimizarem o número de baixas face a este tipo de ameaça.

A utilização de agentes químicos de guerra alargou-se igualmente à sociedade civil, devido à facilidade da sua produção e ao eventual desvio das capacidades das indústrias químicas para fins ilícitos. Esta situação levou à necessidade de implementação de medidas de protecção também ao nível civil.

O Laboratório de Defesa Química (LabDefQE), integrado na componente de Defesa Biológica, Química e Radiológica do Exército com a missão de identificação inequívoca de agentes químicos, constitui-se como órgão fundamental na tomada de decisões médicas, militares e políticas.

Neste artigo são sumarizadas as actividades do LabDefQE, referindo-se determinados desafios técnicos e analíticos inerentes ao processamento de amostras colhidas, em situações envolvendo utilização de agentes químicos.

\section{INTRODUÇÃO}

Em determinada época da evolução da espécie humana, o Homem reconheceu que as substâncias químicas provocavam diferentes efeitos, que lhe poderiam ser benéficos ou prejudiciais [1].

O conhecimento dos efeitos tóxicos de algumas destas substâncias foram posteriormente aproveitados de modo a que estas pudessem ser utilizadas como armas (agentes químicos). Desde então, têm sido assinaladas inúmeras situações de guerra química ao longo da história militar, sendo o caso mais recente, a luta armada na Síria, onde se tem recorrido ao uso de armas químicas, originando inúmeras vítimas.

As Forças Armadas estão sujeitas, quer no Teatro de Operações, quer noutros cenários, a ataques com agentes químicos, sendo necessário avaliar operacionalmente estes riscos, no sentido de minimizar o número de baixas e o insucesso operacional. Torna-se igualmente importante a identificação inequívoca de âmbito forense, principalmente em situações em que haja suspeição de violação de tratados internacionais. A definição exacta do agente químico utilizado possibilita apoiar atempadamente as decisões da NATO e outras decisões políticas e militares.

O recurso aos ataques químicos não se restringe apenas a conflitos militares, sendo igualmente perpetrado por grupos terroristas. Nos últimos anos registaram-se inúmeras ocorrências contra populações, sendo uma das mais paradigmáticas a sucedida em 1995 no metro de Tóquio, onde se fez uso de sarin tendo falecido mais de uma dezena de pessoas [2].

Estas e outras situações demonstraram ao mundo a imprevisibilidade e a facilidade com que pode ser executado um ataque químico. Em condições ambientais adequadas, as armas químicas poderão causar, numa única utilização, um elevado número de baixas, superior ao das armas convencionais; e sendo de muito fácil produção e de baixo custo, são denominadas por muitos como "bomba atómica dos 
pobres" [1]. Por estes motivos, e constituindo a ameaça química uma ameaça latente e real, a Defesa contra estes agentes (Defesa Química) passou a ser objecto de preocupação ao nível governamental e internacional, destacando-se neste caso, a Organização para a Proibição das Armas Químicas (OPAQ).

Portugal dispõe de um dispositivo de actuação para emergências químicas, sob a responsabilidade da Autoridade Nacional de Protecção Civil (ANPC). Em incidentes envolvendo químicos tóxicos abrangidos pela Convenção das Armas Químicas (CAQ), o Exército poderá ser chamado a intervir, através do Elemento de Defesa Biológico Químico e Radiológico (ElemDefBQR), que integra a Equipa Avançada de Defesa Química do Laboratório de Defesa Química do Exército (LabDefQE) [3].

Esta Equipa será a responsável pela recolha forense da amostra química e, já em laboratório, pelo restante processamento e identificação inequívoca do agente. O LabDefQE possui então uma componente fixa ou estrutura laboratorial, e uma componente modular projectável de cariz operacional, a Equipa Avançada de Defesa Química.

Seguidamente são referidas determinadas estratégias de colheita e de identificação analítica praticadas pelo LabDefQE, aludindo-se a questões a ser equacionadas durante o processamento analítico, nomeadamente as inerentes à matriz, às propriedades físico-químicas e ao risco tóxico dos agentes químicos.

\section{Químicos a ANALISAR E SUAS PROPRIEDADES FísICO- -QUÍMICAS}

De acordo com o fim a que se destinam, classificam-se os químicos objecto de análise em três grandes grupos:

- Grupo 1 - Agentes químicos de guerra;

- Grupo 2 - Químicos tóxicos industriais;

- Grupo 3 - Agentes antimotim.

No Grupo 1, agentes químicos de guerra, incluem-se todos os químicos que têm vindo a ser desenvolvidos para fins bélicos, ou seja, para serem utilizados especificamente como armas químicas. Dentro deste grupo incluem-se os agentes neurotóxicos (químicos da série G (tabun, sarin, soman) e série V (VX), os agentes vesicantes (mostardas de enxofre, mostardas nitrogenadas, Lewisites), os sufocantes (fosgénio e cloro) e outros.

No Grupo 2, químicos tóxicos industriais, incluem-se todos os químicos utilizados para fins pacíficos em variadíssimas actividades industriais, como por exemplo a indústria têxtil, a indústria farmacêutica e a indústria agroquímica, mas que pelas suas propriedades químicas/tóxicas poderão ser utilizados, ou isoladamente ou como precursores, para produção dos químicos do Grupo 1, e portanto terem uso como armas químicas. São então químicos de duplo uso, como por exemplo o tiodiglicol, precursor das mostardas de enxofre e utilizado também em indústrias de tintas e plásticos.

No Grupo 3, agentes antimotim, incluem-se alguns químicos utilizados pelas forças de segurança para controlar a ordem pública, com propriedades que provocam incapacidade temporária à exposição, mas que dependendo da dose, poderão originar lesões mais graves. Inclui-se neste grupo por exemplo a cloroacetofenona (CN), vulgo gás lacrimogénio.

Temos então três grupos alvo de análise, compostos sobretudo por substâncias químicas orgânicas, com diferentes propriedades físicas e químicas, podendo ser neutras, básicas ou ácidas; voláteis ou não voláteis; apresentando a maioria átomos de flúor, enxofre, cloro, nitrogénio e oxigénio [4].

\section{Colheita da amostra}

Em situações envolvendo a utilização de agentes químicos de guerra, num conflito armado ou num ataque terrorista, ou noutro tipo de incidentes envolvendo produtos químicos tóxicos, a Equipa Avançada de Defesa Química do LabDefQE poderá ser chamada a intervir.

Esta Equipa, composta por peritos militares químicos, tem a capacidade de se deslocar rapidamente ao terreno com o objectivo de identificar preliminarmente a ameaça e colher amostras (Figura 1A) que serão analisadas com maior rigor científico no LabDefQE. Não menos importante é garantir a não existência de risco tóxico, após processo de descontaminação das pessoas envolvidas e do terreno abrangido pelo incidente (Figura 1B).

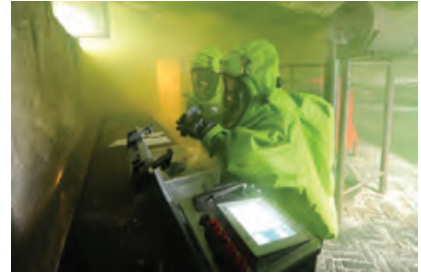

Figura 1A - Amostra colhida por perito do LabDefQE

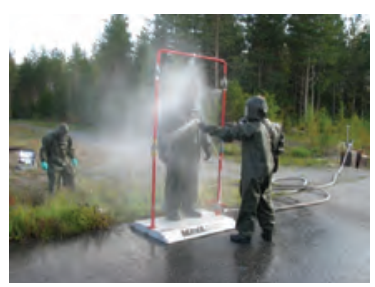

Figura 1B - Descontaminação dos peritos após colheita
A identificação preliminar em campo é realizada com recurso a sistemas de detecção/identificação portáteis de diversos tipos de tecnologia mais ou menos sofisticada, que permitem rapidamente efectuar uma primeira abordagem à classe e grau de concentração do agente químico em causa. O Exército Português possui alguns sistemas de referência NATO, baseados nas tecnologias de infravermelho, espectroscopia de mobilidade iónica, detector de fotometria de chama, entre outros [5].

A boa amostragem é, sem margem de dúvida, a fase mais crítica para que uma análise laboratorial seja bem-sucedida, sendo o conhecimento e experiência do perito (operador da colheita), factores contribuintes para o sucesso [4]. A colheita da amostra coloca desafios que terão que ser superados: 
a. A existência de várias matrizes onde se poderão encontrar os químicos-alvo, como por exemplo:

- Líquidos (água, água do mar, solventes orgânicos, misturas, emulsões,...)

- Solos (areia, argila, relva,...)

- Superfícies (metal, betão, madeira, têxteis,...)

- Gases

- Biológicas (biomédicas, animais e vegetais)

b. O conhecimento das propriedades físico-químicas dos químicos-alvo, face às condições meteorológicas e ambientais;

c. As concentrações em que os químicos se apresentam, na maioria das vezes desconhecidas, podem variar desde níveis vestigiais até a níveis máximos correspondentes aos químicos não diluídos;

d. O número elevado de compostos químicos-alvo a considerar (centenas de milhar) face à Convenção das Armas Químicas [4];

e. A necessidade de protecção individual, na maioria das vezes protecção máxima conseguida com fatos de classe A (classificação EPA/USA), que embora confira máxima protecção e segurança, causa desconforto fisiológico, dificultando a execução de movimentos precisos e minuciosos, tendo igualmente limitação de tempo de uso, ao fim do qual terá de ser removido [6];

f. O preenchimento de uma série de documentos que irão garantir a segurança da cadeia de custódia, em situações que requeiram prova forense (ex: violação de tratados internacionais ou ataques terroristas).

A existência de procedimentos de colheita, devidamente validados, torna-se então obrigatória para evitar erros dificilmente remediáveis [4]. Para além disso, devido ao facto de a maioria dos agentes utilizados como armas possuírem baixa persistência no terreno, algumas horas após a primeira colheita dificilmente se conseguirá efectuar com a mesma eficácia, nova amostragem.
A colheita de amostras biomédicas torna-se obrigatória nas situações em que há necessidade de prova de utilização de determinado agente químico sobre uma população, sendo sempre executada com requisitos forenses.

\section{Preparação da amostra}

Uma boa amostragem e uma estratégia simples e bem planeada de preparação das amostras a analisar são essenciais para alcançar o objectivo com êxito, isto é, a identificação inequívoca do agente químico em causa. Essa estratégia passa inevitavelmente por conhecer a fundo o risco tóxico e as propriedades físico-químicas dos químicos-alvo, para os conseguir separar das matrizes onde se encontram.

Quando possível, a colheita da amostra é acompanhada pela colheita de uma amostra background, correspondente ao mesmo tipo de matriz, mas que garantidamente não contenha o analito suspeito. Esta, tal como o branco ou o controlo, sofre o mesmo processamento que a amostra.

\section{Propriedades dos agentes químicos}

Os agentes químicos de guerra são produtos químicos sintéticos extremamente tóxicos que podem ser dispersos, na forma de gás, líquido ou aerossol, ou como agentes adsorvidos a partículas em forma de pó. Na maioria das vezes são imperceptíveis aos sentidos, possuindo uma acção rápida e persistente após disseminação [6]. O efeito letal do químico é tanto maior quanto: maior a sua toxicidade; mais baixa a sua corrosividade; maior a sua estabilidade química e resistência ao calor libertado no processo de dispersão; e quanto maior for a sua resistência à degradação por factores externos (ambientais). Possuem diferentes características estruturais pertencendo a várias classes de compostos químicos; têm propriedades físico-químicas distintas (tabela 1) e provocam diferentes efeitos fisiológicos sobre as vítimas [6].

De acordo com a sua volatilidade, os agentes químicos classificam-se em persistentes e não-persistentes. Quanto maior a volatilidade de um agente químico, mais facilmente se evapora e dispersa. Os agentes químicos mais voláteis

Tabela 1 - Propriedades físico-químicas dos agentes químicos de guerra (Fonte: ref. 6)

\begin{tabular}{|c|c|c|c|c|c|c|c|c|c|c|c|}
\hline & Tabun & Sarin & Soman & $\mathrm{Vx}$ & $\begin{array}{l}\text { Mostarda } \\
\text { Enxofre }\end{array}$ & $\begin{array}{c}\text { Mostarda } \\
\text { Nitrogenada }\end{array}$ & Lewisite & $\begin{array}{l}\text { Cianeto de } \\
\text { Hidrogénio }\end{array}$ & Cloro & Fosgénio & $\mathrm{CN}$ \\
\hline Massa molar (g/mol) & 162,12 & 140,09 & 182,19 & 267 & 159,08 & 204,54 & 207,32 & 27,03 & 70,9 & 98,92 & 154,59 \\
\hline Densidade Relativa de Vapor & 5,63 & 4,86 & 5,6 & 7,29 & 5,4 & 7,1 & 7,1 & 1,007 & 2,5 & 3,4 & 5,3 \\
\hline Densidade Relativa de Líquido $\left(25^{\circ} \mathrm{C}\right.$ ) & 1,07 & 1,102 & 1,02 & $\begin{array}{c}1,012 \\
\left(\mathrm{a} 20^{\circ} \mathrm{C}\right)\end{array}$ & 1,27 & 1,24 & 1,89 & 0,687 & 1,393 & 1,381 & \\
\hline Ponto de Fusão $\left({ }^{\circ} \mathrm{C}\right)$ & -50 & -57 & -42 & -39 & 14,5 & $-3,7$ & $\begin{array}{c}-18 \\
\text { (trans/cis) }\end{array}$ & $-13,3$ & -101 & -128 & 54 \\
\hline Ponto de Ebulição $\left({ }^{\circ} \mathrm{C}\right)$ & 248 & 147 & $\begin{array}{c}198 \\
\text { (calc.) }\end{array}$ & $\begin{array}{c}298 \\
\text { (decomp.) }\end{array}$ & $\begin{array}{c}228 \\
\text { (decomp.) }\end{array}$ & $\begin{array}{c}256 \\
\text { (decomp.) }\end{array}$ & $\begin{array}{c}190 \\
\text { (trans/cis) }\end{array}$ & 25,7 & -34 & 7,6 & 248 \\
\hline Pressão de Vapor (mm Hg, $25^{\circ} \mathrm{C}$ ) & 0,07 & 2,9 & 0,4 & 0,0007 & 0,11 & 0,0109 & 0,35 & 742 & 5168 & 1180 & $5,4 \times 10^{-3}$ \\
\hline Volatilidade (mg/m $\left.{ }^{3}, 25^{\circ} \mathrm{C}\right)$ & 610 & 22000 & 3900 & 10,5 & 610 & 121 & 4480 & 1080000 & $2,19 \times 10^{7}$ & $\begin{array}{c}4,3 \times 10^{6} \\
\left(\text { a } 7,6^{\circ} \mathrm{C}\right)\end{array}$ & 34 \\
\hline $\mathrm{DL}_{50}$ (pele, mg/kg) & $1-1,5$ & 24 & $10-15$ & $<5$ & 100 & 10 (estim.) & 30 & 100 (liq.) & & & \\
\hline $\mathrm{DL}_{50}$ (respiratória, mg.min $/ \mathrm{m}^{3}$ ) & $135-400$ & $70-100$ & $70-400$ & 30 & $1000-1500$ & 1500 & 1400 & 2000 & $\begin{array}{l}\text { Não exis- } \\
\text { tem dados }\end{array}$ & 3200 & $7000-14000$ \\
\hline
\end{tabular}


como por exemplo o cloro, o fosgénio e o cianeto de hidrogénio (Tabela 1) são agentes não-persistentes, enquanto os menos voláteis, como por exemplo a mostarda de enxofre e o VX, são agentes persistentes [6,7].

De acordo com a estrutura química, alguns dos agentes químicos podem ser classificados em compostos organofosforados, organossulfurados, organofluorados e arsenicais [6].

De um modo geral, recorre-se à classificação dos agentes de acordo com o efeito fisiológico que provocam, sendo esta a classificação adoptada neste artigo. Assim, os agentes químicos utilizados como armas químicas classificam-se em:

- Neurotóxicos;

- Vesicantes;

- Hematóxicos;

- Sufocantes;

- Antimotim.

\subsection{NeUROTÓxicos}

Este grupo engloba os agentes mais tóxicos, com efeitos ao nível do Sistema Nervoso Central, daí a sua designação. Fazem parte deste grupo os agentes da série $G$, como o tabun (GA), sarin (GB), soman (GD) e o VX (estruturas representadas na Figura 2) [6,7].

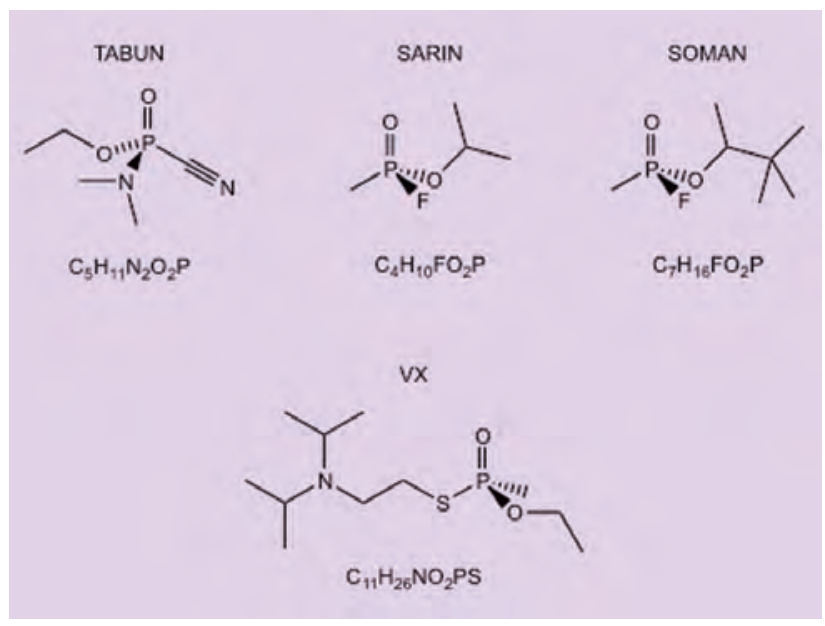

Figura 2 - Estrutura química dos neurotóxicos

São líquidos incolores à temperatura ambiente, e são empregues sob a forma de aerossol a partir do rebentamento de munições que os possuem, ou por aspergimento.

A série $\mathrm{G}$, devido à sua moderada volatilidade, tem como principal via de absorção a inalação, enquanto o VX, por ser um agente de menor volatilidade e de carácter persistente (pode persistir no ambiente até várias semanas após disseminação), é absorvido preferencialmente por via cutânea.

O poder letal destes agentes manifesta-se em geral em escassos minutos, dependendo da dose. Actuam por inibição da acetilcolinesterase, enzima que hidrolisa o neurotrans- missor acetilcolina. Consequentemente, a acetilcolina, responsável pela transmissão do impulso nervoso através das sinapses neuronais, acumula-se nos sítios de transmissão colinérgica, o que leva à superestimulação das estruturas enervadas. Os efeitos dessa acumulação são vários, sendo os mais relevantes: convulsões, depressão respiratória, arritmia cardíaca e fraqueza. Nos casos mais graves, a vítima falece por paragem respiratória.

A elevada toxicidade destes agentes deve-se então à grande afinidade pela enzima acetilcolinesterase, inibindo-a, devido à sua ligação com o grupo químico apresentado na Figura 3. Para se efectuar a união "agente-enzima”, a ligação $\mathrm{P}-\mathrm{X}$ cinde-se.

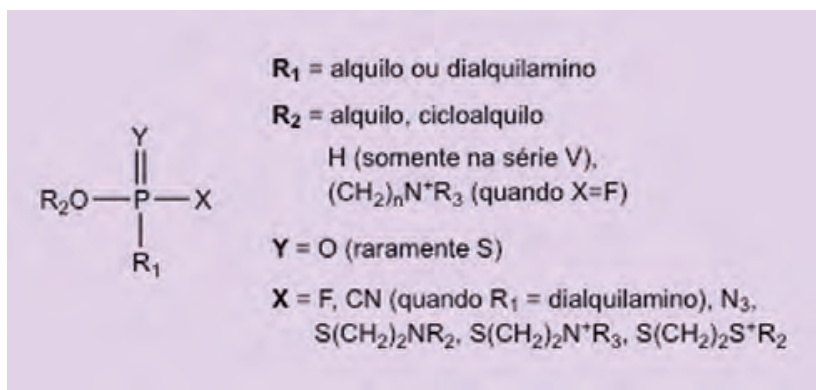

Figura 3 - Fórmula geral dos organofosforados

Quando o grupo de saída X é do tipo - $\mathrm{OR}_{3}$, onde $\mathrm{R}_{3}$ é alquilo ou arilo, a toxicidade diminui. Os agroquímicos organofosforados possuem este grupo [1].

\subsection{VesicAntes}

São compostos tóxicos que produzem lesões ao nível da pele, semelhantes às provocadas pelas queimaduras. Neste grupo incluem-se as mostardas e os arsenicais, sendo a mostarda de enxofre (HD), muitas vezes denominada como o "rei dos agentes químicos", o agente com maior importância histórica. Incluem-se também dentro deste grupo as mostardas nitrogenadas (HN1, HN2 e HN3) e as lewisites (L1, L2 e L3). A Figura 4 mostra as estruturas químicas de vários vesicantes [6,7].

A mostarda de enxofre pura apresenta-se como um líquido inodoro e incolor à temperatura ambiente, contudo na sua forma impura apresenta um odor característico a mostarda ou alho. Possui uma volatilidade muito baixa, é muito solúvel em solventes orgânicos e muito pouco solúvel em água.

As mostardas nitrogenadas puras apresentam-se como líquidos incolores. Em relação às mostardas de enxofre, são menos voláteis, menos solúveis em água e mais resistentes aos agentes de oxidação, embora menos estáveis quando armazenadas.

Os arsenicais (lewisites) puros apresentam-se igualmente como líquidos incolores, possuindo odor metálico. A sua solubilidade em água é semelhante à mostarda de enxofre mas são relativamente instáveis quando armazenados. Assim verifica-se que, tanto as mostardas nitrogenadas como os arsenicais falham num dos critérios básicos do ponto de 


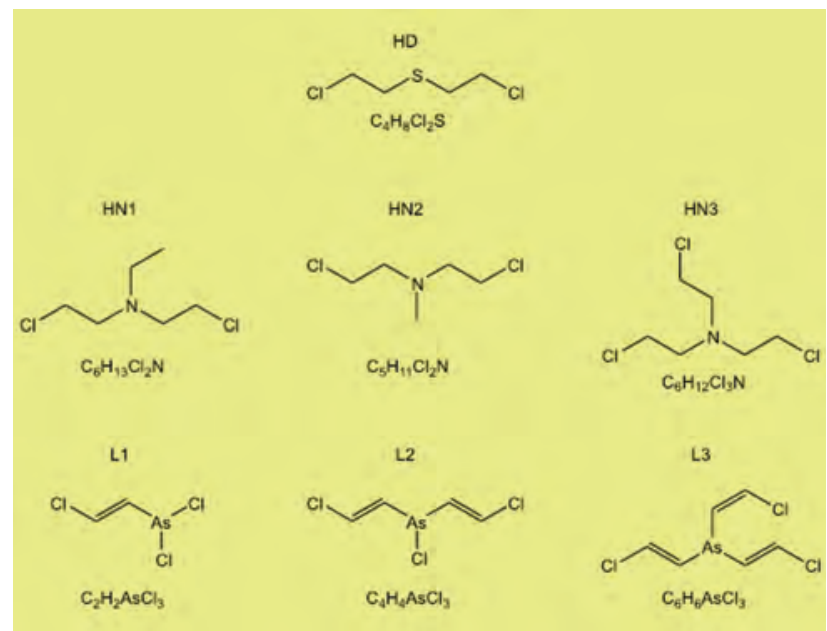

Figura 4 - Estruturas químicas dos agentes vesicantes

vista da sua utilização como armas químicas, degradando-se durante o armazenamento.

As mostardas são lipofílicas e atravessam rapidamente a pele, conseguindo penetrar na maioria dos têxteis e na borracha. São extremamente tóxicas actuando ao nível da divisão celular, possuindo um período de latência de algumas horas, durante o qual não existem efeitos clínicos resultantes da exposição a esses agentes. Este tempo de latência depende da dose, do tempo de exposição e das condições meteorológicas. A principal via de exposição é a pele, em que nos estados mais graves surgem flictenas, e também as mucosas ao nível dos olhos e vias respiratórias.

As lewisites são lipofílicas e são absorvidas pela pele dez vezes mais rapidamente do que as mostardas, com manifestação imediata de dor e eritema.

\subsection{Hematóxicos}

São compostos tóxicos do grupo do cianogénio que actuam ao nível celular através da inibição de certas enzimas mitocondriais, prejudicando a respiração celular. Os mais representativos dentro desta classe são o cianeto de hidrogénio e o cloreto de cianogénio (Figura 5) [6,7].

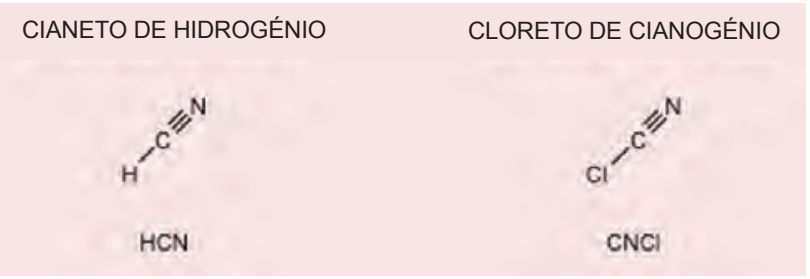

Figura 5 - Estrutura química de agentes hematóxicos

Os efeitos clínicos revelam-se a elevadas doses de exposição e incluem: taquipneia dolorosa, falta de coordenação dos movimentos, irregularidade no ritmo cardíaco, convulsões, coma, paragem respiratória e, por fim, morte.

No seu estado puro, e de acordo com a temperatura ambiente, poderão apresentar-se tanto no estado líquido como gasoso.
A elevada volatilidade dos agentes desta classe restringe a sua utilização como arma química a espaços confinados, como foi o caso do seu uso durante a II Guerra Mundial nas câmaras de gás.

\subsection{SuFOCANTES}

Os agentes sufocantes são químicos tóxicos que actuam principalmente ao nível do tracto respiratório, isto é, nariz, garganta e principalmente nos pulmões. Dentro desta classe destacam-se o cloro e o fosgénio (Figura 6), os mais conhecidos [6,7].

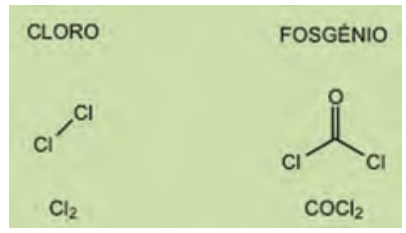

Figura 6 - Cloro e fosgénio

De um modo geral, são mais pesados do que o ar e poderão apresentar-se tanto no estado gasoso como no líquido à temperatura ambiente.

O efeito letal destes agentes depende da dose de exposição e a causa da morte deve-se ao desenvolvimento de edema pulmonar e paralisia do centro respiratório devido a anoxia [7].

\subsection{Antimotim}

Os agentes antimotim são químicos tóxicos, sendo os mais vulgares a cloroacetofenona (CN), o clorobenzilideno malononitrilo (CS) e a dibenzoxazepina (CR) [6,7].

Estes agentes, exemplificados na Figura 7, podem ser classificados de acordo com o efeito que produzem em lacrimejantes (provocam lágrimas e irritação ocular), esternutatórios (provocam espirros e irritação do tracto respiratório superior) e eméticos (causadores do vómito). São sólidos

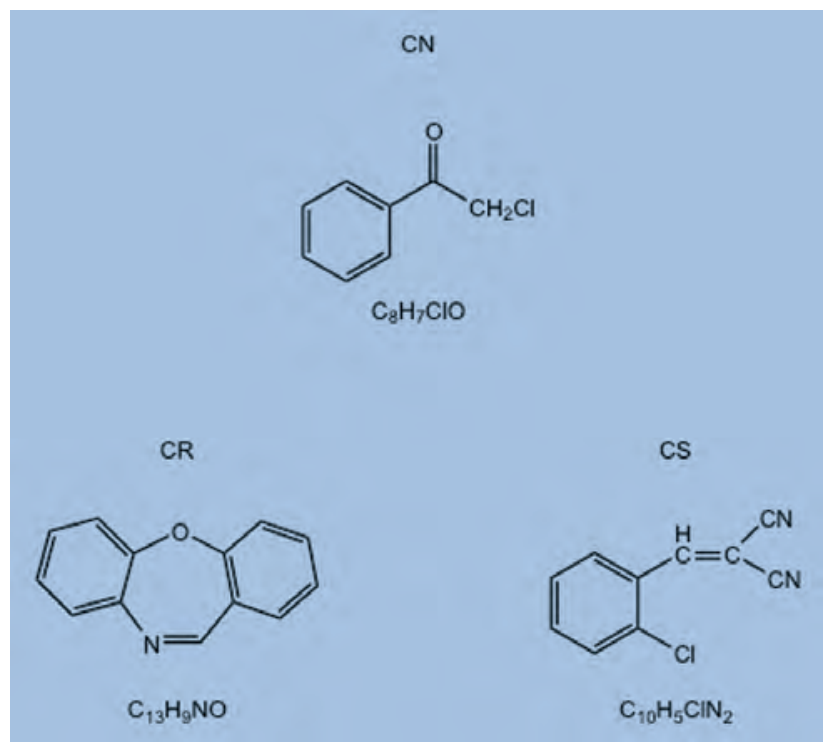

Figura 7 - Estrutura química de agentes antimotim 
à temperatura ambiente, sendo disseminados na forma de aerossóis. São muito pouco solúveis em água, mas solúveis na maioria dos solventes orgânicos. Caracterizam-se pelo rápido início dos efeitos (3 a 10 segundos), curta duração de acção e margem de segurança elevada.

\section{IDENTIFICAÇÃO INEQUÍVOCA DE AGENTES QUÍMICOS DE GUERRA}

Embora a Equipa Avançada de Defesa Química possua algumas indicações acerca do grupo de compostos e grau de contaminação do local do incidente (identificação preliminar), o processo de identificação, propriamente dito, de um agente químico, inicia-se com a recepção das amostras no LabDefQE. O contentor de amostras é recepcionado numa sala de segurança de risco tóxico máximo (sala de pressão negativa) (Figura 8A) e desselado no interior de uma câmara de segurança classe II tipo B2 (câmara de fluxo de ar laminar vertical com 100\% de exaustão - Figura 8B). É igualmente importante garantir previamente a segurança do perito, através de vestuário e calçado protectores adequados ao grau de ameaça, como ilustram as Figuras 8A e 8B.

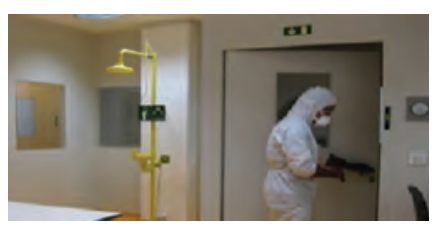

Figura 8A - Entrada para a sala de Figura 8B - Preparação de amostra pressão negativa do LabDefQE

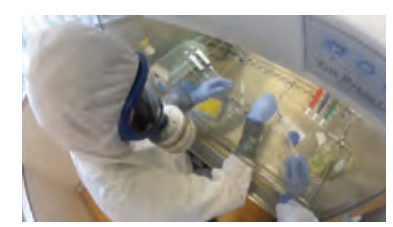

em câmara de fluxo de ar laminar
Após a recepção seguem-se os processos de triagem (screening), preparação da amostra, confirmação e finalmente a interpretação dos resultados.

Qualquer amostra é submetida a uma preparação antes da análise propriamente dita, a fim de se escrutinar todos os agentes químicos, os seus produtos de degradação, de reacção (produtos secundários) ou de metabolização (amostras biomédicas) eventualmente presentes.

O processo de preparação abrange diferentes vias de preparação (screening), dependentes do tipo de amostra, dos agentes a pesquisar e dos métodos analíticos disponíveis. O screening destes compostos inicia-se sempre com a subdivisão da amostra em diferentes fracções representativas (sub-amostras). Cada uma das sub-amostras será então sujeita a diferentes procedimentos, incluindo processos extractivos de acordo com as propriedades físico-químicas dos analitos (polaridade, $\mathrm{p} K_{\mathrm{a}}$, solubilidade, volatilidade, etc.), da matriz onde se encontram e das técnicas analíticas existentes no laboratório [8].

Nos processos extractivos é frequente recorrer-se à técnica SPE (Solid Phase Extraction), com o objectivo de isolar facilmente os químicos-alvo, ou como limpeza da matriz. É o caso da eliminação dos sais (interferentes) presentes no solo que, desta forma, são fácil e rapidamente descartados [8].
Após processo extractivo as amostras são analisadas recorrendo-se na maioria das vezes a técnicas cromatográficas de screening, sendo a GC, GC-MS e LC-MS as de utilização mais comum. Como a maioria dos químicos contidos na CAQ contêm átomos de $\mathrm{P}, \mathrm{S}$ ou $\mathrm{N}$ na sua estrutura, é frequente fazer-se uso de alguns detectores específicos acoplados ao GC, como por exemplo o detetor NPD, FPD, ECD ou AED, que através dos tempos de retenção relativos (t.r.r.) de químicos-padrão, poderão indiciar de um modo rápido, a presença dos analitos alvo. Não havendo um detector de máxima sensibilidade para todos os compostos, devem submeter-se as soluções a diferentes detectores em paralelo, mantendo contudo as mesmas condições cromatográficas, nomeadamente o mesmo tipo de fase estacionária utilizada. Deste modo, consegue-se obter rapidamente a máxima informação, comparando os sinais obtidos nos diferentes detectores a um mesmo tempo de retenção [8].

Em muitos casos a derivatização (técnica de microssíntese) é utilizada como método pré-preparativo para análise por cromatografia gasosa. A derivatização executa-se essencialmente para conferir maior estabilidade térmica aos analitos que apresentam polaridade e elevada volatilidade, favorecendo igualmente a especificidade e a sensibilidade na sua detecção, visto que na maioria das vezes se encontram em concentrações ínfimas (na ordem das ppm/ppb).

O LabDefQE utiliza técnicas espectrométricas acopladas à cromatografia gasosa e à cromatografia líquida, auxiliando-se igualmente de alguns detectores sensíveis e específicos, como o detetor NPD, de nitrogénio e fósforo.

A Figura 9 mostra a marcha analítica em prática pelo LabDefQE para amostras de solo, visualizando-se as diferentes vias de extracção, consoante a técnica analítica a utilizar (GC ou LC), e dentro destas, os procedimentos destinados a identificar os agentes abrangidos pela CAQ [9]. Assim, por exemplo refere-se: o processo de limpeza com resinas de troca catiónica (por $S P E$ ) a que uma das subamostras é submetida, a fim de retirar o excesso de sais presentes no solo; os processos de derivatização por sililação ou por metilação, sendo a primeira destinada aos compostos com grupos -OH ou - $\mathrm{COOH}$, como os produtos de degradação dos neurotóxicos, e a metilação dirigida aos compostos com grupos $\mathrm{N}$ e $\mathrm{S}$, existentes nos agentes mostarda [8].

Depois do screening de compostos há que confirmar os resultados positivos presuntivos. Para obtenção de um resultado inequívoco, uma amostra tem que ser analisada pelo menos por duas técnicas analíticas diferentes, sendo uma delas obrigatoriamente uma técnica espectrométrica.

Muitos dos laboratórios designados pela OPAQ utilizam como técnicas analíticas confirmatórias principais a de GC-MS por impacto electrónico (EI) e a de GC-MS por ionização química (CI). O LabDefQE faz uso destas duas técnicas (Figura 10A). A confirmação é então realizada por GC-MS-EI com interpretação e comparação de espectros de massa do analito face a dados de referência e por GC-MS-CI que atesta a sua massa molecular [8]. 


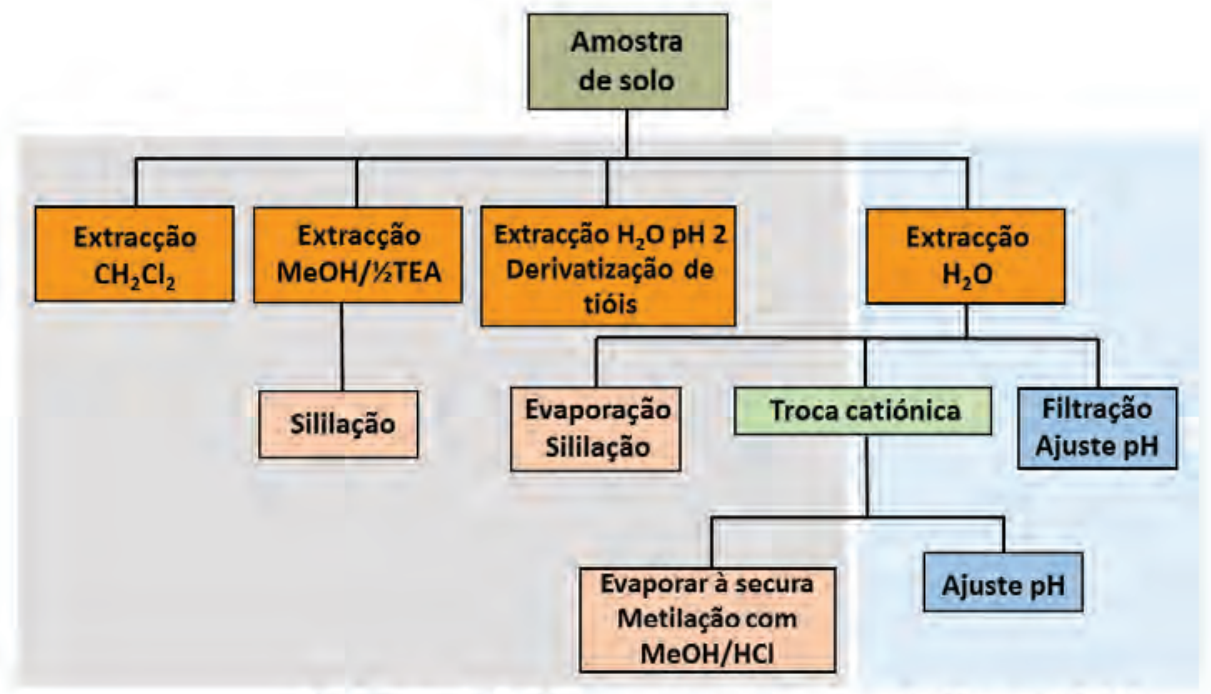

Análise por GC-MS

Análise por LC-MS

Figura 9 - Diferentes tratamentos das várias porções de amostra de solo (Fonte: ref. 8])

Para além da tecnologia GC-MS, o LabDefQE dispõe também de um LC-HRMS (espectrómetro de alta resolução), visualizado na Figura 10B, técnica recente e inovadora, que permite detectar massas dos compostos até à quinta casa decimal.

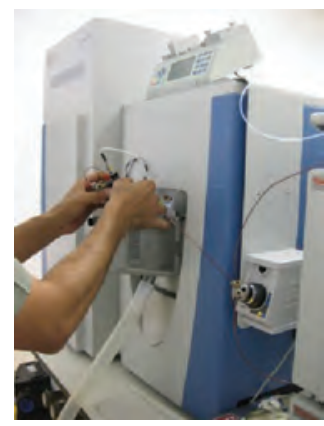

Figura 10A - GC-MS (modo EI ou CI)

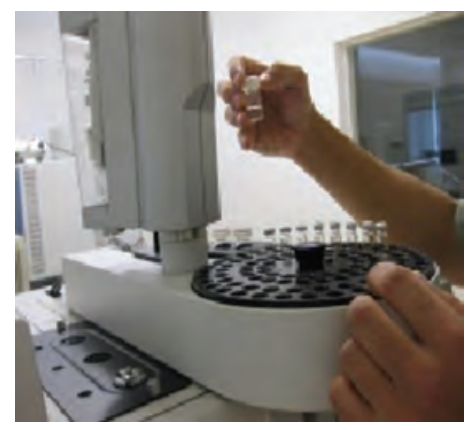

Figura 10B - LC-HRMS
Padrões de referência de agentes químicos, seus precursores e produtos de degradação são necessários para se poder emitir um resultado inequívoco. Este é um dos desafios que se coloca aos laboratórios deste tipo, uma vez que, como é óbvio, não é fácil a aquisição destes compostos tóxicos, por quase ausência de comercialização, havendo frequentemen-

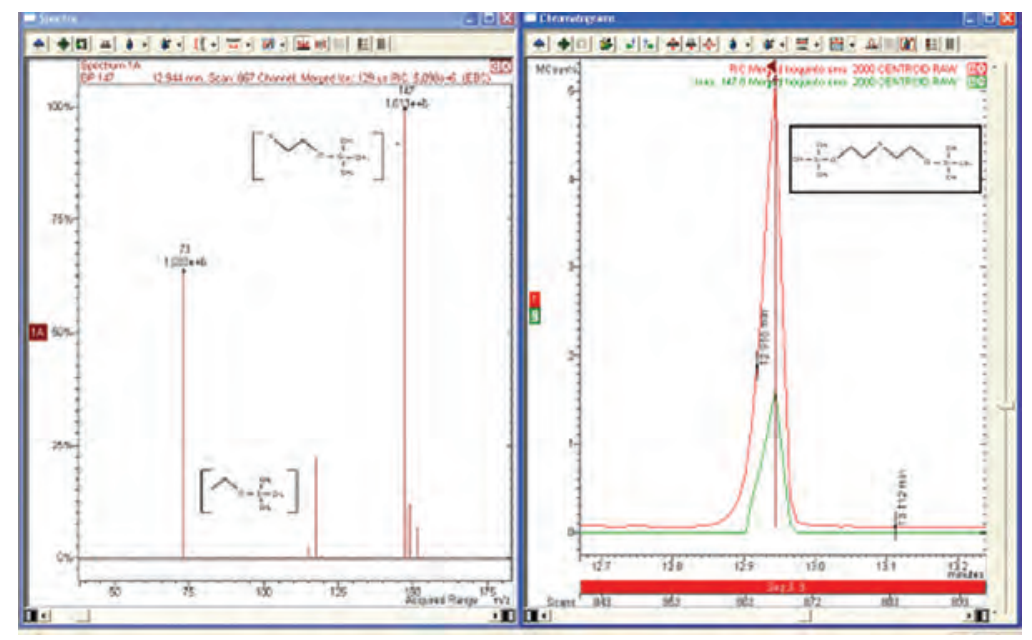

te a necessidade de efectuar a síntese de determinados compostos alvo para que se possa garantir o resultado analítico.

Um resultado inequívoco obriga então à avaliação rigorosa de todo o processamento da amostra desde a fase de amostragem até ao resultado final, que passam pelo equacionamento de diversos factores que poderão pôr em causa o seu sucesso, a saber:

- O agente químico poderá não se encontrar com a estrutura intacta, apresentando-se como um ou mais produtos de degradação ou de reacção. Os agentes químicos, na maioria dos casos, degradam-se após libertação ou reagem originando novos compostos, devido às suas propriedades físico-químicas, às condições meteorológicas, às condições do terreno, ou ao tempo que decorre entre a libertação e a colheita. As soluções químicas entretanto eventualmente aplicadas no terreno como descontaminantes, poderão igualmente provocar uma maior decomposição do agente, levando em casos extremos ao desaparecimento do mesmo;

- A coexistência de quantidades excessivas de interferentes (agentes mascarantes) como por exemplo insecticidas, adubos, tintas, entre outros, que por se encontrarem em grande concentração, mascaram a presença dos agentes químicos/produtos de degradação;

- A existência de milhares de químicos que terão de ser considerados e que não se encontram descritos na CAQ $[4,8]$.

De notar que os produtos da degradação dos agentes são, na maioria das vezes, também precursores da sua síntese. A Figura 11 exemplifica o espectro de massa e cromatograma obtidos por GC-MS do tiodiglicol

Figura 11 - Imagem de espectro de massa e cromatograma do tiodiglicol (derivatização por BSTFA) obtido por um dos GC-MS do LabDefQE 
(após derivatização por sililação), principal precursor e produto de degradação das mostardas de enxofre.

Em suma, os principais desafios inerentes à identificação inequívoca de agentes após incidente químico dizem respeito, essencialmente, ao elevado número de agentes químicos a considerar, às suas diferentes características e concentrações; à existência de matrizes variadas e complexas; à necessidade de efectuar a análise de cada amostra com pelo menos duas técnicas analíticas diferentes (uma das quais espectrométrica); à possibilidade de inexistência do perfil de fragmentação do analito em biblioteca e à necessidade de realização de síntese do mesmo para confirmação da identificação, devido à indisponibilidade do respectivo padrão.

\section{Conclusões}

Os incidentes químicos constituem uma ameaça permanente, exigindo por parte dos responsáveis militares e governamentais, um empenho contínuo na actualização dos mecanismos de protecção e defesa contra novas ameaças, e consequentemente na formação e treino das Forças Armadas e entidades civis.

O LabDefQE, parte da componente de Defesa BQR do Exército, tem vindo a desenvolver estratégias de colheita e identificação analítica de agentes químicos que possibilitam, no menor intervalo de tempo, efectuar a avaliação operacional do risco tóxico. Configura-se como laboratório único ao nível nacional, por congregar a capacidade laboratorial com a operacional, através da projecção modular de peritos ao terreno do incidente.

O LabDefQE encontra-se igualmente envolvido em áreas relevantes e inovadoras tais como: a avaliação de risco tóxico através da descoberta de novos marcadores biológicos (biomarcadores); o desenvolvimento de meios de descontaminação mais eficazes; a melhoria de equipamentos de protecção individual ou o desenvolvimento de novas tecnologias mais eficazes de detecção no terreno. Decorrem neste momento projectos I\&D ligados a algumas destas áreas.

Apesar das várias actividades associadas à sua missão, em situações reais envolvendo vítimas, o LabDefQE desempenha igualmente um papel preponderante no apoio à decisão médica, na confirmação do diagnóstico e na monitorização clínica.

\section{LISTA DE ABREVIATURAS}

AED - Atomic Emission Detector

ANPC - Autoridade Nacional de Protecção Civil

CAQ - Convenção das Armas Químicas

CI - Chemical Ionization
ECD - Electron Capture Detector

EI - Electronic Impact

ElemDefBQR - Elemento de Defesa Biológico Químico e Radiológico

EPA/USA - Environmental Protection Agency/United

States of America

FPD - Flame Photometric Detector

GC - Gas chromatography

HRMS - High Resolution Mass Spectrometry

I\&D - Investigação e Desenvolvimento

LC- Liquid Chromatography

LabDefQE - Laboratório de Defesa Química do Exército

MS - Mass Spectrometry

NATO - North Atlantic Treaty Organization

NPD - Nitrogen Phosphorus Detector

OPAQ - Organização para a Proibição das Armas Químicas

ppb - partes por bilião

ppm - partes por milhão

SPE - Solid Phase Extraction

\section{Agradecimentos}

Aos militares do LabDefQE pelos contributos prestados na elaboração deste artigo.

\section{REFERÊNCIAS}

[1] G. Silva, I. Borges Jr., J.D. Figueiroa-Villar, A. T. de Castro, Quim. Nova, 10 (2012) 2083-2091

[2] World Health Organization (WHO), "Public health response to biological and chemical weapons: WHO guidance $2^{\text {nd }}$ edition”, WHO, Geneva, 2004

[3] ANPC, "Directiva Nacional Operacional n. ${ }^{\circ} 3$ - NRBQ: Dispositivo Integrado de Operações Nuclear Radiológico Biológico e Químico”, ANPC, Carnaxide, 2010

[4] M. Mesilaakso, "Chemical Weapons Convention Chemical Analysis: Sample Collection, Preparation and Analytical Methods”, John Wiley \& Sons Ltd, Chichester, 2005

[5] R. Sferopoulos “A Review of Chemical Warfare Agent (CWA) Detector Technologies and Commercial-Off-TheShelf Items”, Defense Science and Technology Organisation, Victoria, 2009

[6] K. Ganesan, S.K. Kaza, R. Vjayaraghavan, Journal of Pharmacy \& BioAllied Sciences, 2 (2010) 166-178

[7] NATO, "AMedP-6(C) Handbook on the Medical Aspects of NBC Defensive Operations -VOL. III - Chemical”, NATO, 2006

[8] P. Vanninen, "Recommended Operating Procedures for Analysis in the Verification of Chemical Disarmament", University of Helsinki, Helsinki, 2011

[9] Organisation for the Prohibition of Chemical Weapons (OPCW), "Convention on the Prohibition of the Development, Production, Stockpiling and Use of Chemical Weapons and on their Destruction”, OPCW 